Erratum

\title{
Erratum to "A Bioinformatics Pipeline for the Analyses of Viral Escape Dynamics and Host Immune Responses during an Infection"
}

\author{
Preston Leung, Rowena Bull, Andrew Lloyd, and Fabio Luciani \\ Inflammation and Infection Research Centre, School of Medical Sciences, The University of New South Wales, \\ Sydney, NSW 2052, Australia \\ Correspondence should be addressed to Fabio Luciani; luciani@unsw.edu.au \\ Received 19 August 2014; Accepted 1 September 2014; Published 21 September 2014 \\ Copyright (C) 2014 Preston Leung et al. This is an open access article distributed under the Creative Commons Attribution License, \\ which permits unrestricted use, distribution, and reproduction in any medium, provided the original work is properly cited.
}

In the paper titled "A bioinformatics pipeline for the analyses of viral escape dynamics and host immune responses during an infection," there was an error in Figure 5. This figure has the two Circos plots identical. In this erratum we report the corrected Figure 5 where the upper right Circos plot has been replaced with the corrected figure. 


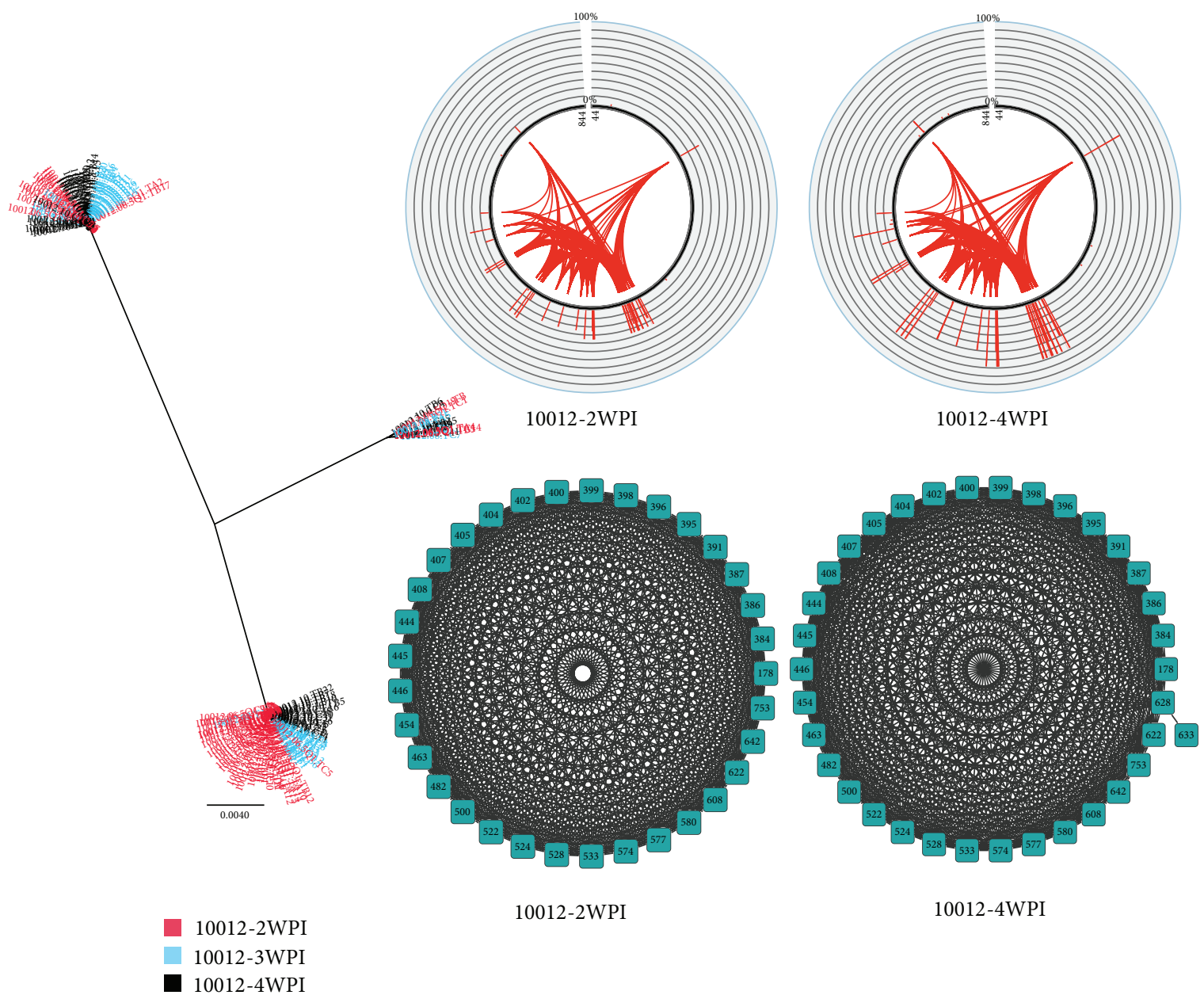

FIGURE 5: A representative example of a HCV infection presenting highly diverse viral population. Single genome amplification (SGA) data from longitudinally collected HCV populations over three time points (2, 3, and 4WPI) taken from a subject (10012) infected with HCV genotype 1a. This analysis was based on sequences from partial Core protein, p7, E1, and E2 protein, of HCV from 2WPI and 4WPI (3WPI not shown). Unrooted phylogenetic tree displays three major subpopulations of viruses. A substantial viral diversification is observed since 2 weeks after infection. During this early stage of infection it is unlikely that HCV specific T-cell and B-cell responses are targeting the infection. However, the Circos plots highlight the presence of highly connected variants with specific patterns of cooccurring mutations. This is further validated from the covariance network showing high number of pairs of sites, which are maintained during the early phase of infection. 

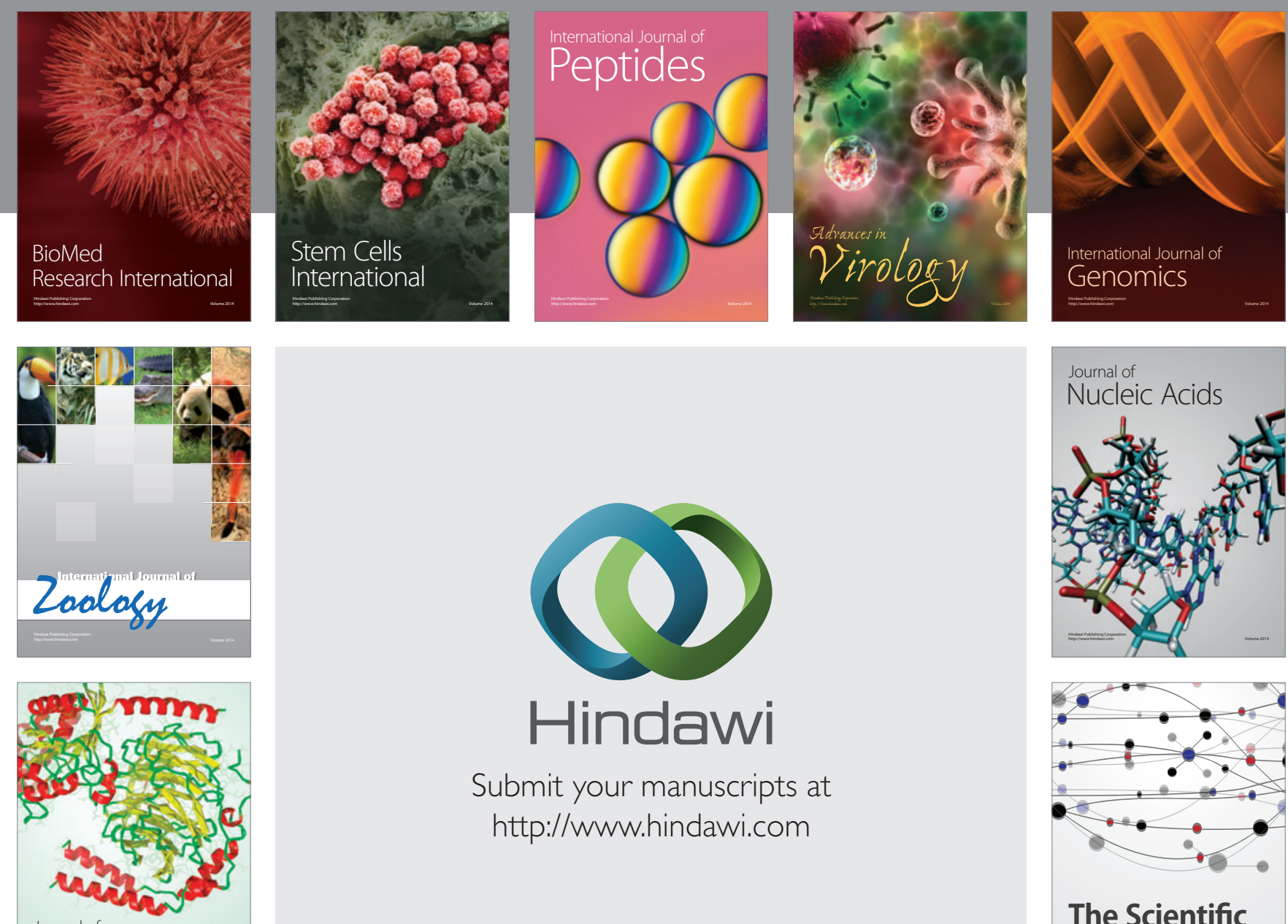

Submit your manuscripts at

http://www.hindawi.com

Journal of
Signal Transduction
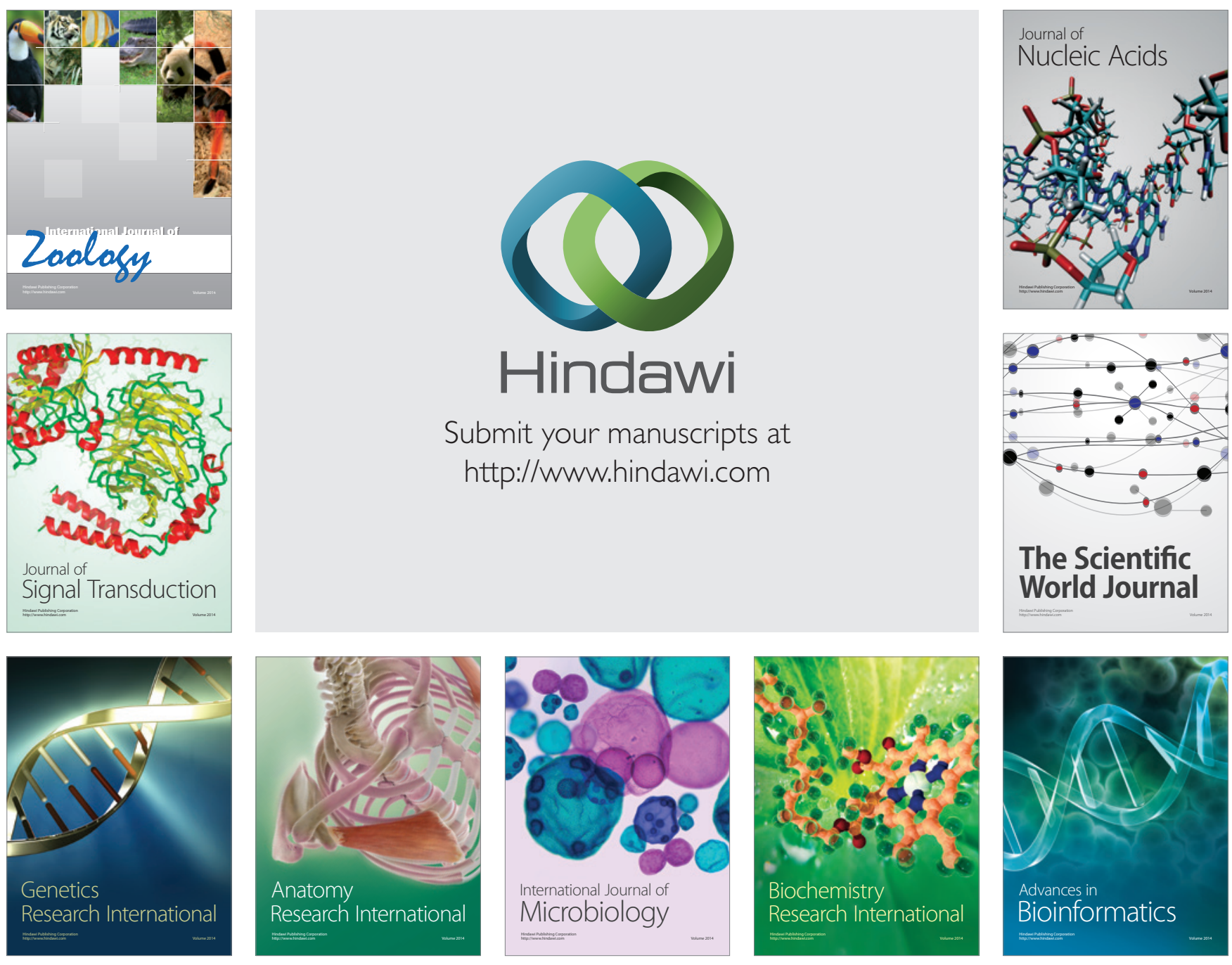

The Scientific World Journal
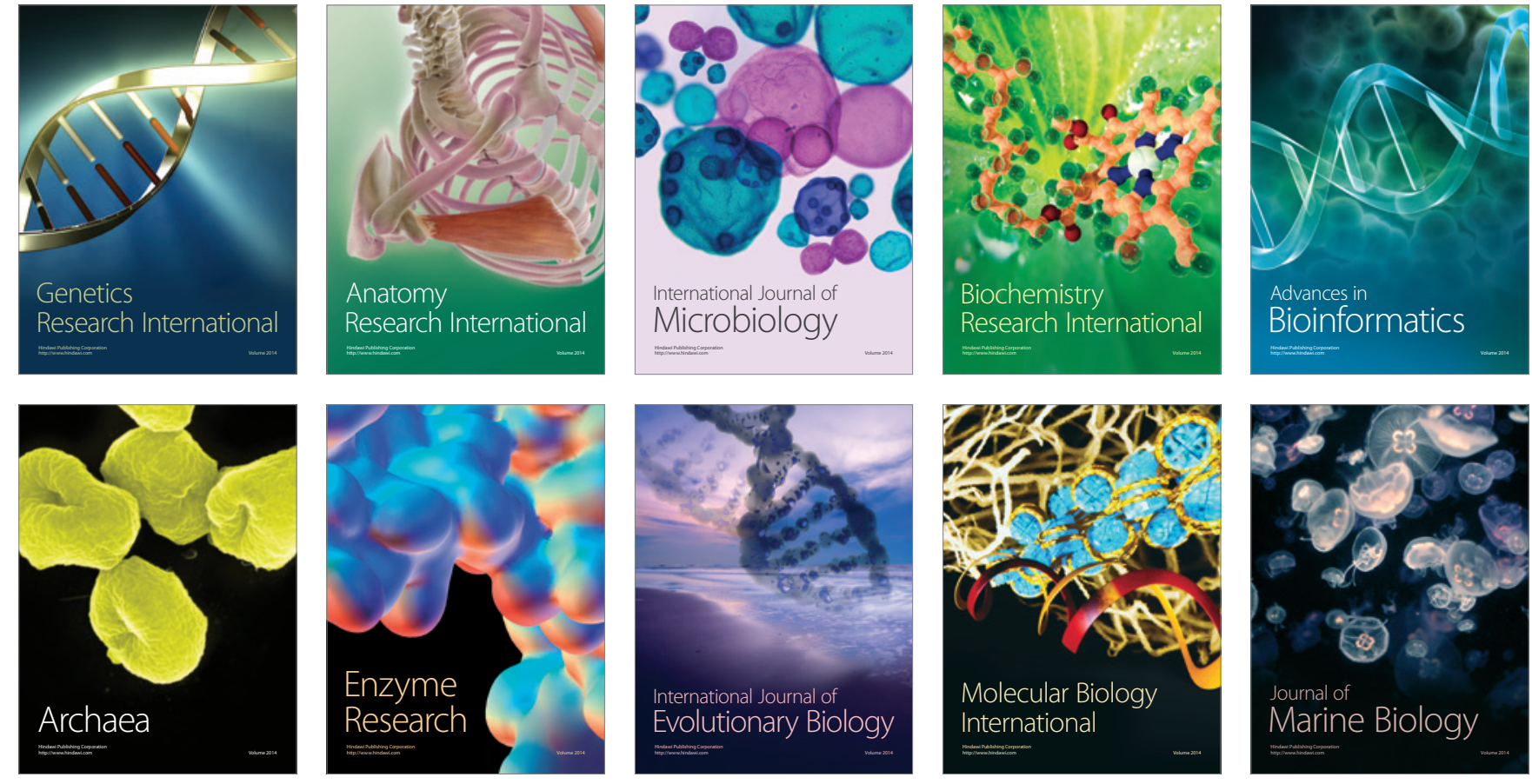